\title{
Conservation, animal behaviour, and human-animal relationship in zoos. Why is animal welfare so important?
}

\author{
Isabel Escobar-Ibarra ${ }^{a}$ | Daniel Mota-Rojas ${ }^{a *}$ (iD | Fernando Gual-Sill ${ }^{a, b *}$ (iD | \\ Carlos R. Sánchez $^{\mathrm{c} \text { (D) | Fidel Baschetto }}{ }^{\mathrm{d}}$ | María Alonso-Spilsbury
}

${ }^{a}$ Neurophysiology, behaviour and animal welfare assessment. DPAA. Universidad Autónoma Metropolitana (UAM), Unidad Xochimilco, Mexico City, Mexico. birección General de Zoológicos y Conservación de la Fauna Silvestre. Secretaría del Medio Ambiente -SEDEMA, Mexico City, Mexico.

Oregon Zoo - Veterinary Medical Center, Portland, Oregon, U.S.A.

Universidad Libre del Ambiente \& Universidad Nacional de Villa María, Córdoba, Argentina.

*Corresponding author: dmota100@yahoo.com.mx; f.gual.sill@gmail.com; maspilsbury@hotmail.com

\begin{abstract}
Although zoos are committed to wildlife conservation and have a long-term positive impact on visitors' attitudes towards wildlife, the question of whether maintaining wild animals in human care is justified remains as animal welfare concerns grow and human understanding of animal intelligence and capacities broadens. Zoos have always been the subject of debate, with conflicts between those who argue they save endangered species and educate visitors, and animal rights activists who believe that conditions of wild animals are inadequate and that zoos should not exist. In this review, we do not discuss the moral side of the issue, but the scientific one. This manuscript aims to show the scope of literature available on the strengths and weaknesses of modern zoos regarding wild animal welfare. We provide information useful to argue why zoos are important in modern society and factors that influence welfare are examined. Some potentially stressful stimuli may diminish animal welfare in zoo animals, while some of the benefits zoos offer to conservation and science include the opportunity to study and learn about different aspects necessary to improve management practices; the possibility of breeding wild animals in zoos has been a key factor in the recovery of species that have improved their conservation status. Animal welfare is an essential part of wildlife conservation, so efforts should be directed to ensure the best possible quality of life and optimum conditions of all zoo animals in our care.
\end{abstract}

Keywords animal welfare, ex-situ conservation, wildlife conservation, zoos

\section{Introduction}

Saving or protecting a habitat (in situ conservation) is not always effective or achievable in the short term. Yet, there are other strategies for endangered species conservation including ex situ conservation (in zoos, aquaria, and botanical gardens), rational/sustainable use, invasive species control, science and research, conservation education, and ecotourism (Hutchins 2001). Zoos around the world have evolved from being the "menageries" from the XIX century, where exotic animals were simply exhibited in cages, going through the live museums of the $X X$ century, into real centres of conservation in the XXI century (IUDZG/CBSG 1993 Nowadays, the concept of Integrated Conservation / One Plan Approach / Sorta situ is developed in zoos; it links both ex-situ and in situ conservation strategies through different tools or activities including conservation of wild populations, science and research, population management, conservation education, and training, communication (marketing and training), collaboration (partnerships and politics), sustainability, ethics and animal welfare (WAZA 2005; Byers et al 2013; Barongi et al 2015).

Generally speaking, some of the contributions of zoos to the conservation of wild species include the reproduction and reintroduction of endangered species, environmental / conservation education (zoos represent the first contact with nature for millions of people), isolation from threats like diseases (e.g. chytridiomycosis in amphibians) or competition with other species, generation of information useful for the management of wild individuals and species (ISIS, PVA's, Studbooks), basic research (veterinary medicine and diseases, behaviour, biology, genetics, reproduction, nutrition, wellbeing, management, etc.). Additionally, alliances with universities/institutes, raising funds for conservation programs, providing opportunities for marketing and public relations strategies, local education (in situ), involvement in environmental policy, field projects and skills training, capacity building and development (Zimmermann 2010; Conde et al 2012; Gusset and Dick 2012).

This manuscript aims to show the scope of literature available on the strengths and weaknesses of modern zoos regarding wild animal welfare. We provide information useful to argue why zoos are important in modern society and factors that influence welfare are examined.

\section{Modern zoos key objectives}


Formerly, modern zoos around the world played four main roles: conservation, education, entertainment and research. The majority of zoo visitors go, at least in part, for entertainment [Reade and Waran 1996; Altman 1998; Karanikola et al 2004; Davey 2007; Ouan and Zakariz 2007; Yasuda 2013; Roc and McConney, 2015), or because of biophilia, an instinctive bond of human beings to other live organisms (Lee 2015). Zoos give us the illusion of proximity to wild animals because they keep live animals (Safina 2018). Nowadays, zoos are encouraged to become models of integrated conservation; zoo professionals including animal care specialists, conservationists, educators, communicators, wildlife advocates, and scientists, must become agents of change and promote the One Plan Approach; to fulfill this responsibility zoos must engage in several aspects such as connecting conservation activities in zoos with wild populations while developing other tools including science and research, population management, education and training, communication, collaboration, sustainability, ethics and animal welfare (WAZA 2005; Byers et al 2013; Barongi et al 2015).

\subsection{Role of zoos in recreation}

The vast majority of zoo visitors attend in social groups, with family members, or on school field trips. Social interactions are thus a key part of the zoo visitor experience and when people are looking at the animals, there seems to be an almost automatic tendency to share the experience with others, generating opportunities to create and communicate shared values (see Figure $1 \mathrm{~A}$ ). Evidence that the zoo has spent time considering the animals' needs, not just for food but for intellectual stimulation and social interactions, reminds the visitor that animals have such needs, that they are thinking entities with their own experiences and not just objects for human entertainment (Clayton 2016).

\subsection{Role of zoos in education and research}

Conservation and science education is the core of many zoos' mission. In the past 30 years, many zoos had been deeply involved with conservation and research efforts, studying animal welfare, biology, and behaviour both in situ and ex-situ, while integrating animal welfare standards and policies to ensure that animal welfare is guaranteed at their facilities.

Zoos can complement traditional education (i.e., learning spaces and experiences, interpretive and interactive displays, graphic panels, immersive exhibits) with focused conservation education messages, which cover both the cause of conservation threats as well as what people can do to help (Falk 2005). For instance, the conservation education campaign 'Don't Palm Us Off' implemented at Melbourne Zoo, Australia, for visitors of the orangutan exhibit, resulted in a significant increase in palm oil awareness with 160,000 people signing an associated petition for mandatory palm oil labeling (Pearson et al 2014).
Species threatened by habitat loss will not be safe unless suitable ecosystems are protected and those at risk from poaching will not be safe until people's attitudes and behaviours change. In the meantime, zoos create awareness among the public about the nature of animals and make people foster an appreciation and respect for animals. Given that there are over 700 million visitors to zoos and aquaria every year, a significant contribution is made even if only one-third of these visits result in an improved understanding of biodiversity and conservation. Nevertheless, Nygren \& Ojalamuni (2018) conclude in their conservation education review that it is urgent to widen the view of nature conservation, human-animal relations (HAR), and environmental education in zoos since the reviewed zoo visitor literature does not take a critical enough stance on the zoos' conservation views, which point to a rather narrow set of practices and view of HAR. Zoos need to better understand not just why people go there: they should be more concerned about what visitors do after they leave, they need to better inspire visitors' active engagement for animals, welfare, and conservation (Safina 2018).

It has become popular among certain circles to question the value of breeding wild animals in zoos and reintroduction programs for endangered animals. However, it should be recognized that there are many more immediate ways that zoos and their living collections can contribute to conservation beyond breeding wild animals for reintroduction, including as mentioned above, public education and scientific research. The Associaton of Zoos and Aquariums (AZA) as one of their key accreditation criteria, has the implementation of conservation research. One recent study by Loh and co-authors showed that members of this organization publish a significant number of manuscripts classified as "biodiversity conservation" (approx. 7\% of all publications annually) (Loh et al 2018). The number of peerreviewed manuscripts increased overtime during the period of this study (1993-2013). Although not all publications may be conservation relevant, the research produced by zoos and aquariums contributes to the body of scientific research on which evidence-informed conservation action and management is based (Sutherland et al 2004; Arlettaz et al 2010) (see Figure 1B).

The majority of research conducted in zoos focuses on mammals (Maple and Bashaw 2010); as an example, Miller et al (2014) had quantified the energetic requirements of Amur tigers (Panthera tigris altaica), which allow resource managers to estimate nutritional carrying capacity, estimate the impact of tigers on prey, and develop science-based conservation recommendations. One specific example of the contribution of research activities in zoos is in elephant conservation. In addition to providing support to in situ conservation projects, zoos conduct ex situ research that directly benefits free-ranging elephants from the development of non-invasive sampling techniques and analytical tools to pharmacology, nutrition, sensory biology, and reproductive research studies (Bechert 2019). 


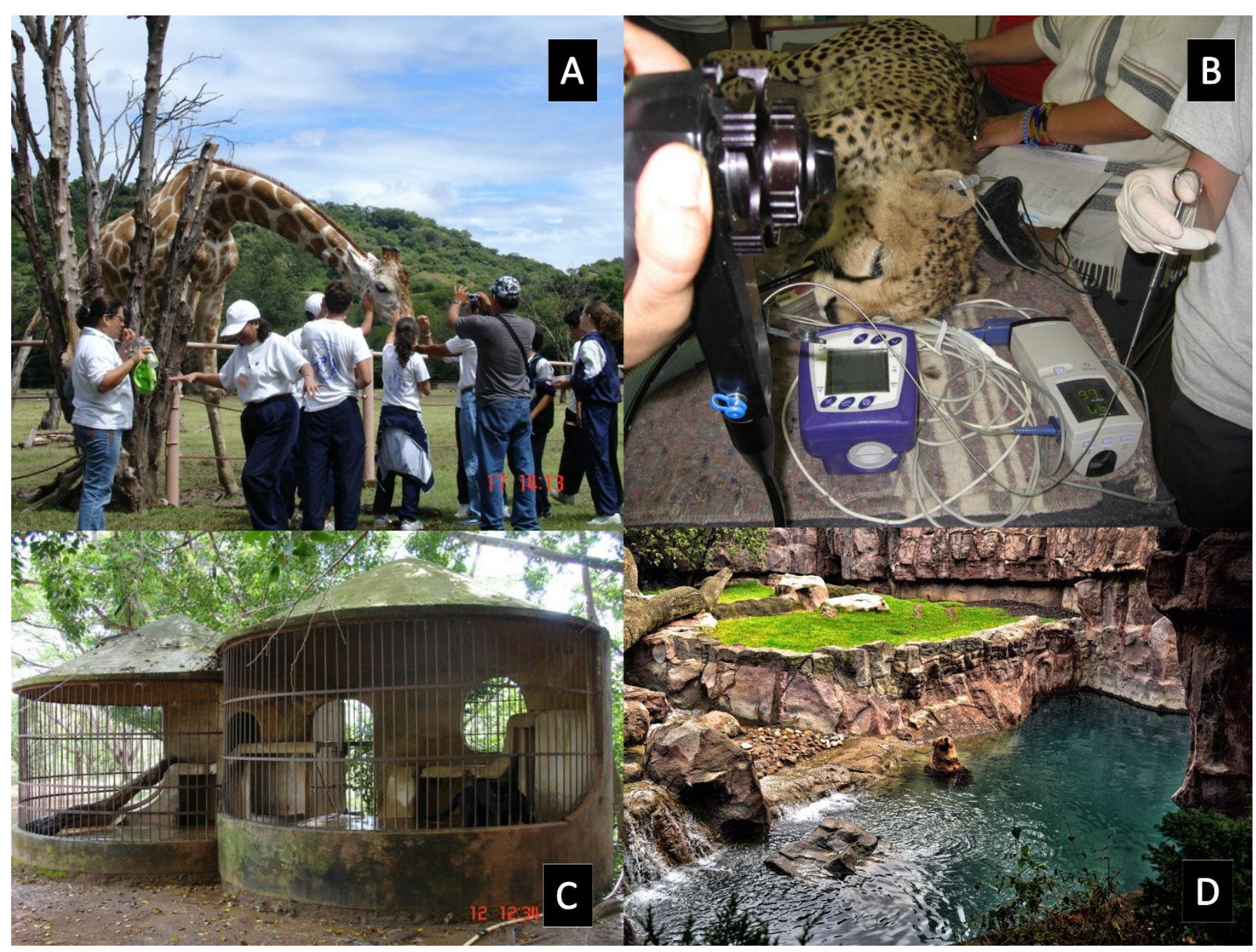

Figure $1 \mathrm{~A}$. Zoo educators rely on interactive experiences to create a bond between visitors and endangered species. B. Zoos promote research in different aspects of animal health and management and facilitate the training of many professionals working in field conservation projects. C. Black jaguar confined in an inappropriate space of barren concrete and metal bars with no enrichment. D. The environmental enrichment programmes in zoos include the design of naturalistic exhibits. Photo credits A, C: M. Alonso-Spilsbury. B: C.R. Sánchez. D: A. Rodríguez / Chapultepec Zoo.

\subsection{Role of zoos in wildlife conservation}

It has been estimated that to achieve viable ex situ populations of vertebrates in general, a sample of enough size to keep $90 \%$ of genetic diversity for 100 years is required, which implies that 250 to 500 individuals of the same species are needed to establish a reproductive program in zoos. Considering half of the space of 1,000 well-established zoos around the world, which keep approximately 1,000,000 wild animals in human care, these zoos could support the conservation of 1,000 to 2,000 species (IUDZG/CBSG 1993). Generally speaking, zoos do not keep an important number of individuals of the same species, but the community of zoos as a whole keeps viable populations for reproduction and recovery programs. Conde et al. (2011) studied ex situ populations of wild species with more than 250 individuals, noting that $24 \%$ of amphibian species, $21 \%$ mammals, $8 \%$ of birds, and $6 \%$ of reptiles kept in zoological institutions have populations large enough for viable ex situ conservation programs. Roughly, 1 out of 7 species of endangered terrestrial vertebrates (almost 15\%) is kept in zoological institutions. Also, reproduction of wild animals in human care has been key to the recovery of between 13 and 19 species out of a total of 64 that improved their conservation status in the last few years, mainly mammals and birds (Hoffmann et al 2010; Conde et al 2011; Gusset and Dick 2012). Strategic collection planning should be a priority to ensure that each animal at every zoo has a role to play in conservation, education, and/or research programs and that all species that require the support of ex situ management, have access to this valuable space for collaborative breeding programs based in zoos. For this purpose, modern zoos, first and foremost need to ensure the well-being of the animals in their care (Young 2003).

As stated before, animal welfare is an essential tool of the World Zoo and Aquarium Conservation Strategy. All zoos must maintain the highest standards of animal welfare to establish and sustain viable populations of healthy animals for conservation purposes and ensure credible conservation messages to all visitors (WAZA 2005). Nevertheless, some authors consider that animal welfare is not taken into account within the general context of conservation (Arias 
2011). Multiple conflicts between animal protectors and conservationists arise constantly since most animal rights advocate freedom; some conservationists, on the other hand, accept reductions in animal welfare when the survival of entire populations or species is at stake (Keulartz 2015). It has also been suggested that a policy focused on the welfare of individuals from the point of view of species conservation is not ethical, since it leads to conflicts between individual welfare and that of populations (Kagan 2010). However, it should be noted that public perception regarding the use and maintenance of animals in human care is not based on scientific evidence (McGrath 2013): some people do not view keeping animals in zoos for public display as defending biodiversity, so care must be taken that decisions are based on a scientific base. Nevertheless, a zoo animal welfare framework has been designed to facilitate a sustainable, science-based, and compassionate approach that ensures better welfare for animals in zoos and aquariums (Kagan et al 2015; Kagan et al 2018). These same authors state that science, common sense, and compassion must be used when evaluating the well-being of wild animals under human care.

Some possible strategies for promoting care and conservation at the same time, according to Palmer and Sandøe (2016), include keeping fewer species in larger numbers and keeping more local species. Local and endemic species are adapted to the local climate, and the animals will be less stressed by reintroduction into the wild if it is not far to travel. If population sizes are larger, there is less need to move animals for conservation breeding programs, and bigger, more specialized facilities that would provide better welfare are possible. Nevertheless, a recent study shows that visiting zoos and aquariums contributes to the conservation of wild species. Certain factors such as a big number of animals, the presence of large animals, high species richness (particularly of mammals), and the inclusion of dissimilar (unusual) animals, correlate with higher numbers of visitors and with the contribution of these zoos to more in situ conservation projects (Mooney 2020). Given the importance of the presence in zoos of many of these species for conservation, we must ensure the welfare of all wild individuals in human care.

\section{The sorta situ Approach}

With persistent and new challenges and threats, wildlife populations are facing a new global reality with rapidly changing landscapes and a decreasing vailability of truly wild areas. Because of this, animals are now, more than ever, managed in protected areas, refuges, and conservation centers as such the distinction between ex-situ and in situ conservation becomes less apparent. The term sorta situ has been recently used to describe a combination of ex situ developed skills (e.g: health management, advanced reproductive techniques, etc) linked to field (in situ) skills such as reintroduction techniques and community-based conservation, amongst others. Zoos have played, and continue to play a vital role in this approach. The Baltimore zoo (now Maryland zoo) was instrumental to the creation of the Mountain Gorilla (Gorilla beringei beringei) Veterinary Project in protected areas in this species' range countries. Similarly, projects like the California Condor Recovery Program rely on zoos for the treatment of lead-poisoned birds that, once treated, are released back to their territories. The strict ex-situ or in situ approach that until now zoos have used in the field of conservation may not be enough to meet some species' conservation needs. Approaching conservation with this - neither one or nor the other - sorta situ perspective reflects the evolving nature of the role of zoos in wildlife conservation itself as a reflection of the new global reality for wildlife species (Wolfe et al 2012). This view of conservation resembles the One Plan Approach / Integrated Conservation through which species population management bridges the gap between wild and intensively managed populations (Byers et al 2013).

\section{Naturalization of zoos}

As stated before, zoos are necessarily involved in the protection of endangered species, some of which are no longer abundant or became extinct in the wild; these institutions provide spaces free from the pressures of habitat loss, starvation, and predators. Ensuring animals are housed in appropriate social groups is critical to welfare. While pursuing these goals, enclosure designs and maintenance are difficult and costly tasks; the main challenge is their naturalization, which consists of simulating the natural surroundings of wild animals to favor specific behaviours in different species in human care (Keulartz 2015), providing protection as well. While there are good intentions and in some zoos, the employees make a great team that works in synergy with the facilities, actually many public and some private zoos still maintain the same conditions they had at the beginning of the XX century. Some of these zoos keep animals in obsolete and inadequate enclosures with elements that generate stress, such as bar cages with concrete floors (see Figure $1 \mathrm{C}$ ), due to insufficient economic resources invested in improving their facilities (Lee 2015).

\subsection{Enclosure size and complexity}

Wild individuals in zoos face no threat from predators and are not exposed to the daily stress of finding food and shelter, but instead may experience negative social interactions due to confined space and lack of cover (van der Weyde et al 2016). Inadequate enclosure sizes for displaying animals have been linked to aggression (Li et al 2007) and stereotyped pacing (Brummer et al 2010).

Breton and Barrot (2014) showed a positive correlation between the size of the enclosure and the total distance covered by 38 tigers (Panthera tigris) in human care; tigers covered longer distances in the evening compared to the morning just like wild tigers, which are generally on hunt in the evening and have to travel more for that purpose. Authors observed that the larger the enclosure, the more distance tigers cover and the less they pace. Similarly, Vaz et 
al (2017) observed that tigers require larger natural habitats, while leopards (Panthera pardus) can manage even with smaller isolated patches covered with dense vegetation.

Small enclosure size has a negative impact on the behaviour of wombats (Descovich et al 2012). Clouded leopards (Neofelis nebulosa) reproductive success in human care has been poor and Wielebnowski et al (2002) observed increased glucocorticoid concentrations in individuals with small enclosure heights and limited keeper contact. However, enclosures for amputees (Malayan bears, Helarctos malayanus) can be smaller than those for able-bodied bears but should still contain a variety of climbing structures (Lewis et al 2018).

In other cases, the basic biological characteristics of animals are ignored when, for example, nocturnal species are kept in enclosures without an inverted light-darkness cycle (Ladeia and Young 2015). Tennant et al (2018) showed that $39.29 \%$ of institutions in the USA secure their hippos (Hippopotamus amphibius) in holding areas overnight, despite their highly active nocturnal propensities.

Another issue is that it is almost impossible to recreate in a zoo the vast extension of natural habitats. Furthermore, in the case of felines, natural predator behaviour such as stalking and killing prey cannot be allowed as it was up until the seventies, when live sheep, goats, rabbits, and birds were placed in enclosures for this purpose. This practice was banned due to visitors describing it as unacceptable (Keulartz and Veasey 2013). All these factors lead to a greater vulnerability of animals to many stressors, both acute and chronic (Majchrzak et al 2015).

Abiotic factors like olfactory, visual, auditory, tactile, and thermal environments (Morgan and Tromborg 2007) are important but are not always considered by zoological facilities, even though we should know that they contribute to an animal's perception of their quality of life (Kagan et al 2018). Well-designed zoos can support animal training, adequate husbandry, and health care, and improve animal welfare; these facilitate environmental enrichment and physical exercise promoting more behavioural choices, resulting in greater self-determination (Coe and Dykstra 2010).

Zoo landscaping can add variety and a naturalistic sense of zoos (Jackson 1990) (see Figure 1D). Provision of a naturalistic 3-dimensional enclosure, preferably including tree trunks, facilitates natural climbing behaviour, in addition to functioning as a nail sharpening tool for big cats (Moreira et al 2007). Pomerantz et al (2013) showed that providing appropriate social stimuli and increasing the complexity of the environment of zoo-housed primates, rather than enlarging it, are both attainable and expected to improve the animals' welfare. Moreover, many modern keeping facilities provide hiding places that allow animals to withdraw from the sight of conspecifics, visitors, or keepers. Mallapur et al (2005) observed that adding some trees and logs to serve as shelter and hideouts has reduced the stress level of macaques; incorporating the use of ropes and vines also stimulates animal activity. Bonnie et al (2016) demonstrated that well-designed zoo exhibits can be effective in removing the potentially aversive effects of large crowds on apes. Wild animals in zoos may benefit from having the choice to utilize multiple types of habitat, depending on their natural biological tendencies (Schultz and Young 2018).

An understanding of a species' behavioural ecology and natural history is fundamental to identify those factors in husbandry, management, and facilities in zoos likely to be linked to the individual's well-being. The human may not detect certain stressors such as odors, but exposure to fumes from disinfectants, urine, dust, and other factors that may affect dramatically individual welfare of zoo animals. Sometimes we expose species to inappropriate sounds, temperatures, artificial lighting, light cycles, social structures, novelty, proximity to predator or prey species, and husbandry and force them into human presence. Thus greater knowledge and sensitivity to how animals perceive and experience life in zoos will help prevent the effect of stressors in the individual welfare of wild animals in human care (Morgan and Trombirg 2007; Kagan and Veasey 2013). People in charge of these wild populations in zoos must understand and develop the concept of otherness and the ability to change their perspective for that of the other individual. In this case according to the animal's point of view, to see the situation of each animal from its perspective, taking into account the species to which it belongs and not from the point of view of the human being (that is to avoid anthropomorphization). This aspect implies conceptualizing and assessing the environment (facilities, management, etc.) according to the biology, habits, behaviour, natural history, and other attributes of each species, and a great professional responsibility, training, and constant updating of all the people in charge of wild animals in human care for the benefit of their welfare. We need to recognize those animals in zoos as sentient beings with their own emotions and desires. The opportunity for zoos lies in transforming themselves from traditional animal displays to interactive, entertaining conservation centers that bridge the gap between their exsitu collections and free-ranging wildlife (Tribe and Booth 2003); future zoos and aquariums must make sure that all animal environments (physical, psychological, and social) are outstanding for the animals first and foremost (Kagan et al 2018).

The use of advanced Global Positioning System (GPS) technology to track individual positions within an exhibit has been used in elephants (Horback et al 2012). The utilization of tracking devices in animal behaviour research may help animal caretakers, and zoological exhibit designers, to better understand and incorporate species-specific needs to promote welfare.

\section{Human-animal relationship at the zoos}

Many activities in zoos involve animal interactions with visitors, from riding to feeding or just walking inside the exhibit and a significant number of different species, ranging from giraffes (Giraffa camelopardis reticulata) to reptiles, are 
involved in animal interactions. Visitors are not allowed to irritate or tease animals or try to harm them, but occasional incidents may happen. Teasing and harassment constitute negative interactions, reducing the quality of the HAR with zoo visitors, and possibly other people including keepers (Hosey and Melfi 2015).

The human-animal interface in zoos has been intensively evaluated and includes a wide breadth of interactions with caretakers, researchers, and visitors that have been shown to exert some influence on animal behaviour and well-being (see Hosey (2008)). Visitors have different effects on the visited animals, which according to Hosey (2009), can be categorized in three classes: a) Stressful decreasing animal welfare (on Borneo orangutans (Pongo pygmaeus) [Amrein et al 2014]; jaguars (Panthera onca) [Montenha et al 2009]; chamois (Rupicapra rupicapra tatrica) [Zwijacz-Kozica et al 2012]; black-capped capuchin (Sapajus apela) [Sherwen et al 2015]); the animals showing hostile and aggressive responses (arboreal small monkeys [Chamove et al 1988]; gorilla (Gorilla gorilla) [Well 2055]; blackbuck (Antilope cervicapra) [Sellinger and $\mathrm{Ha}$ 2005]; penguins (Eudyptula minor) [Sherwen 2015b]), decreased social behaviour (chimpanzees (Pan troglodytes) [Wood 1998]; lion-tailed macaques (Macaca silenus) [Mallapur et al 2005]; drills (Mandrillus leucophaeus) [Lundin 2013; Lindblom 2014]), increased vigilance (koalas (Phascolarctos cinereus) [Larsen et al 2014]), increased abnormal behaviour and stereotypies (Indian leopard (Panthera pardus fusca) [Mallapur 2002]; mandrils (Mandrillus sphinx) [Chamove et al 1988]; jaguar [Mallapur et al 2005]; gorilla [Wells 2005; Carder et al 2008]; brown bears (Ursus arctus) [Soriano et al 2013]) or hiding from the public (gorilla [Kuar 2008]; harbour seals (Phoca vitulina) [Stevens et al 2013]). Larsen et al (2014) suggest that research on the welfare implications of closeencounters with koalas, particularly the petting experience that some parks or zoos offer to visitors, is urgently needed.

Furthermore, the loud and unruly behaviour of some visitors can have aroused and provoking effects on zoo animals. Visitors' noise has been found to increase with visitor numbers, making it difficult to determine the actual cause of changes in animal behaviour [Sellinger and $\mathrm{Ha} 2005$ ]. Quadros et al (2014) observed that zoo visitors have a negative welfare impact on individual zoo-housed mammals, especially groups of noisy visitors where levels were recorded outside of the recommended limits for human wellbeing ( $>70$ $\mathrm{dB})$.

A second and positive effect of visitors according to Hosey (2000) corresponds to b) Enriching, promoting animal welfare (chimpanzees [Baker 2004; Claxton 2011]; blacktailed prairie dog (Cynomys ludovicianus) [Eltorai and Sussman 210]; meerkats (Suricata suricatta) [Scott 2014], by increased vigilant behaviour while reducing inactive behaviour (deer (Elephurus davidanius) [Li et al 2007]; coyote (Canis latrans), [Schultz and Young 2018]), increasing feeding (Asian small-clawed otter (Ambionyx cinerea) [Owen 2004]; giant panda (Ailuropoda melanoleuca) [Soriano et al 2013]) or decreasing stereotypies (Asian elephants (Elephas maximus) [Robson 2004]). A recent study on camels (Camelus dromedarius) in Toronto Zoo concluded that visitors riding the camels can be considered a way of environmental enrichment that mitigates the effects of keeping this species in zoos. Cortisol levels were lower during this period than when animals took a break from the activity; the authors attribute this effect to exercise (Majchrzak et al 2015).

Caretaker - animal relationships are relevant to wild animals' health and emotional well-being (Chelluri et al 2013). Positive keeper actions resulted in calm and confident giraffes with a willingness to interact, whereas negative interactions resulted in more anxious and startled giraffes (Giraffa camelopardalis rothschildi) who were more easily distracted (Patel et al 2019). However, if the animal has experienced a lot of different keepers, they have likely had less opportunity to form a positive HAR (Hosey and Melfi 2015). Finding ways to improve HAR in zoo settings will only result in positive outcomes for animal welfare, thus it is important to continue investigating techniques that help to cultivate strong, positive caretaker-animal relationships (Chelluri et al 2013) (see Figure 2A).

The third effect of public on animals (Hosey 2000) is c) Neutral effect, with lack of significant change in behaviour that is likely to have little impact on animal welfare (chimps and gorillas [Bonnie et al 2016]; cheetahs (Acinonyx jubatus) [O'Donovan et al 2003]; African lion (Panthera leo) [Margulis et al 2003]; rhea (Rhea americana) [de Azevedo et al 2012]; kangaroos (Macropus giganteus) [Sherwen et al 2015]; numbats appear not to respond strongly to anthropogenic disturbances (Hogan et al 2012). According to Patel et al. (2019), methods utilizing 'latency', 'qualitative behaviour assessment' and the 'voluntary approach test' are potentially viable to assess HARs in a zoo environment, however, they still require empirical testing and comparisons within a zoo environment.

\section{Animal behaviour, stereotypies and environmental enrichment}

Regarding animal behaviour within zoos, the neurobiological development of each species should be given special attention. As mentioned above, the environmental and husbandry needs of a domestic species have little to do with those of a wild feline or a primate. Routine welfare assessment often needs to be rapid, non-invasive, and should not require any specialist equipment, facilities or specific training of animals; for this reason, routine welfare assessment is often based on observations of behaviour (Yon et al 2019). Besides, behavioural observations provide a rapid and non-invasive method to recognize stress in animals. Regarding animal behaviour within zoos, the neurobiological development of each species should be given special attention. Restrictions in the ability to perform normal species-specific behaviours may lead to stress and frustration, both detrimental to welfare. In a study, Warwick et al (2013) refer to 30 behaviour-based signs of stress in reptiles, as well as quiescence or comfort. 
Conservation efforts by zoos can be hindered by the presence of behavioural changes such as stereotypies, which are repetitive conducts performed with no apparent function, in zoo animals (Kelly et al 2015; Keulartz 2015). The expression of these behaviours may also be influenced by individual variation, enclosure features, or by external factors (Morgan and Tromborg 2007).

There are different categories of abnormal behaviours (Fox 1968; Garner 2005; Mason 2010), including a) Impulsivecompulsive behaviours (i.e. self-biting and self-mutilation, regurgitation and re-ingestion (in bonobos (Pan paniscus) [Miller and Tobey 2012]); abnormal mother-offspring bond (infanticide) and prolonged infantile behaviour or exaggerated aggressiveness, abnormal sexual behaviour (i.e. substitute sexual objects) or auto-grooming (in orangutans [Amrein et al 2014]), and b) Stereotypies (i.e. head movements: head-toss; body balancing; wall and bar licking, sucking or biting and tongue flicking, and pacing).

Of particular concern are the relatively high prevalence and rates of stereotypic behaviour shown by zoo elephants (e.g., swaying, weaving, pacing [Mason_and Veasey 2010]), felids [Quirke et al 2012; Vaz et al 2017], primates [Pomerantz et al 2012], bears [Soriano et al 2017], polar bears (Ursus maritimus) [Shepherdson et al 2013]) found $85 \%$ of bears in their study performed the behaviour and it used up an average of $11 \%$ of the activity budget, and minks (Polanco et al 2018), among others. Broom (1983) suggested that it is unacceptable for any animal to spend more than $10 \%$ of the waking day displaying abnormal behaviours.

Visitors may perceive pacing to be a negative behaviour (Miller 2012), not understanding the complex nature of the behaviour; usually, they relate it to inferior care at the current host institution even when it may be a relic of an animal's previous living conditions (Mcphee and Carlstead 2010) and typifying zoos as suboptimal environments (Mason 1991). Although the occurrence of stereotypic behaviour may insinuate insufficient or poor welfare, it may be serving innate biological or physical functions (Mason 1991). Moreover, highly stereotypic individuals often show better welfare than less stereotypic conspecifics housed in similar sub-optimal conditions (Mason and Latham 2004).

Wide-ranging carnivore species exhibit more stereotypic locomotive behaviour in zoos compared to species with smaller natural home ranges (Clubb and Mason 2003; Clubb and Mason 2007). Tigers enjoy vast hunting territories and travel great distances daily in the wild; this species shows an increased risk of developing stereotypies, including hyperactivity, inactivity, toe and tail sucking, headtwisting, excessive grooming, fur plucking, and head-tossing (Mohapatra et al 2014).

The specific social characteristics of each species must be considered as a factor in the development of stereotypies. Polar bears, for example, do not form social groups in the wild, and males and females only meet briefly to breed in summer, while ex-situ they are kept together, leading to the increased presence of these conducts (Kelly et al 2015). Overcrowding is known to increase the risk of agonistic interactions between animals which, in turn, may require additional physiological defense mechanisms. Individual variations can explain inter-individual differences in behavioural welfare measure outcomes too, for example, aberrant repetitive behaviours were significantly lower in bold and zoo-raised individuals compared to wild-rescued and shy lions (Goswami et al 2020).

The application of animal behaviour knowledge to pressing environmental problems gave rise to the subdiscipline of conservation behaviour barely two decades ago (Fernández-Juricic and Schulte 2016), with cognitive mechanisms playing an important role. Moreover, comparative cognitive research run in zoos is gaining momentum, with more zoos becoming involved and a greater diversity of species being studied (reviewed by Hopper, [Hopper 2017]). One of the aims is to promote compassion and humane approaches to the control of overly abundant species, and the restoration of endangered species (Marzluff and Swift 2017). In this sense, compassionate conservation (Bekoff 2013; Gray 2017; Gray 2018) suggests we consider a different approach to saving species.

There is growing evidence that animal welfare is improved by the performance of a species' typical behaviours. An environmental enrichment program that addresses these behavioural needs can reduce stress and stereotypic behaviour; for instance, a reduction in the incidence of stereotypies was associated with larger enclosures in the brown bear (Montaudouin and Pape 2004), while enrichment eliminated stereotypies in polar bears (Shepherdson et al 2013); Mohaptra et al (2014) found that environmental enrichment such as feeding boxes, live fish in pools, complex feeders, cardboard boxes, and urine from opposite-sex animals, among other strategies, reduced stereotypies in tigers in human care. Environmental enrichment was originally defined as a fundamental principle of animal husbandry that improves the quality of life through the identification and provision of environmental stimuli necessary for an optimal psychological and physiological well-being (Shepherdson 1998). Nowadays this concept includes the process of improving the environment and husbandry of zoo animals in the context of behavioural biology and the individual's natural history. It is a dynamic process that promotes infrastructure changes (e.g. the presentation of food items or manipulable objects) and husbandry practices (e.g. rotating a species through different exhibits) to increase the different alternative behaviours available to animals and promote adequate abilities and conducts, thus improving well-being (Shepherdson 2010) (see Figure 2B). Given the limited physical space a zoo can offer, environmental enrichment has more to do with an increase in the psychological space of an individual.

Another important aspect of enrichment is the routine and systematic evaluation of responses to it using appropriate methods (including non-invasive tools) to obtain quantitative data on the applied techniques, which allows assessing improvements to the individual well-being. Interactions between zoo professionals and animals occur 
regularly and are believed to be enriching for animals. Furthermore, repeated exposure to situations that involve human contact is likely to lead to the habituation of animals, which in turn promotes their well-being (Sherwen et al 2014). Operant conditioning techniques are used for animal training, based on positive reinforcement, to facilitate medical procedures and to obtain biological samples to monitor the health of individuals of different species of wild animals kept in zoos and aquariums (elephants, rhinoceros giraffes, felines, and other large carnivores, non-human primates, dolphins, and sea lions, among others). These techniques are considered an enrichment strategy with positive outcomes for the animal, its keepers, and veterinarians, aiding in their handling and reducing both the risks associated with interacting with such animals to staff and the inherent risk of physical and chemical immobilization (Laule and Desmond 1998) (see Figures 2C and 2D).

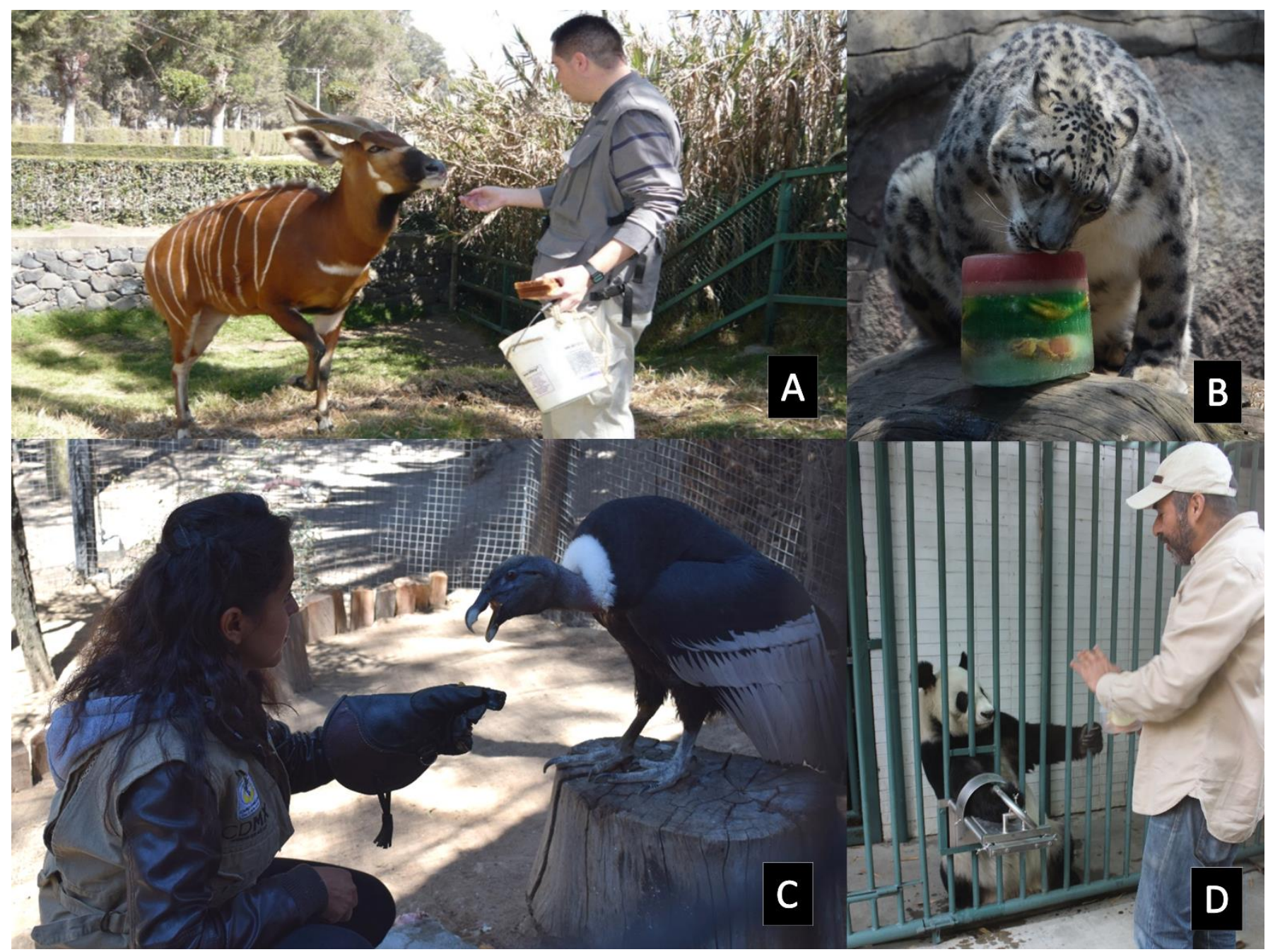

Figure 2 A. Positive caretaker - animal relationship avoids stress in routine care and facilitates training of zoo animals. B. Behavioural enrichment activities in zoos improve individual animal welfare and favour learning experiences in zoo visitors. C, D. Operant conditioning / Positive reinforcement techniques are used to train different species of wild animals in zoos to reduce stress and avoid the need of chemical immobilization for health screenings and medical procedures. Photo credits A: M. Alonso-Spilsbury B, C: A. Rodríguez / Chapultepec Zoo; D: F. Gual-Sill.

\section{Ex-situ breeding of critically endangered species}

Wildlife centres, wild animal breeding facilities, national parks, and other protected natural areas, have been instituted to conserve endangered species (eg. de Wildt Cheetah and wildlife center in South Africa, [Bertschinger et al 2008]). Maintaining high reproductive success in zoos is essential for instance, for Amur, Malayan, and Sumatran tigers, as each is thought to number fewer than 500 individuals in the wild (Saunders et al 2014).
For many species, human care is increasingly important. Conservation breeding involves ex situ propagation of endangered species to help maintain genetic diversity, produce viable individuals for release, and ultimately mitigate species' extinction (Conde et al 2011). Exsitu breeding should start when there is still a healthy wild population if we are to secure genetically diverse founders and create programs with a reasonable chance of success; creative and collaborative approaches are needed to ensure that appropriate human care is included in the tools of compassionate conservation (Bekoff 2013; Gray 2017; Gray 
2018). Besides, it has been suggested that zoos devote at least $10 \%$ of their income to in situ conservation (Tribe and Booth 2003).

Beginning in the 1980s, the zoo community developed the Species Survival Plans (SSP's). These documents coordinate breeding and population management programs for threatened and endangered animals among zoos worldwide. According to the AZA, SSP's and related programmes have helped in bringing the black-footed ferrets (Mustela nigripes), California condors (Gymnogyps californianus), red wolves (Canis rufus), Mexican gray wolves (Canis lupus baileyi), and several other endangered species back from the brink of extinction over the last three decades. The SSP for lowland gorillas (Gorilla gorilla gorilla), Andean condors, giant pandas, and snow leopards, among others, have not had such clear success (Scientific American 2009). Tigers, for example, are severely threatened in their native habitat, but due to their popularity in zoos and their unproblematic ex situ reproduction, their survival as a species is secured (Gross 2012).

The black-footed ferret conservation program started in 2001, California condors were reintroduced in Mexico by 2002, and Mexican gray wolves were reintroduced first in Arizona, in 1998, with animals bred at ex-situ facilities in Mexico and USA (List 2005), and more recently in 2011 in Mexican territory; these three species are Mexican ex-situ conservation examples of success and collaboration (Lascuráin et al 2009). (See Figure 3A) Ex-situ breeding of the California condor has been the main tool to save this species from extinction. Between 1982 and 1987, the last 27 condors in the world founded the only breeding population in zoos; currently, the total California condor world population totals almost 500 individuals. More than $60 \%$ of these condors are living in the wild in California, Arizona, Utah (USA), and Baja California (Mexico). Institutions such as Los Angeles Zoo, San Diego Zoo, Santa Barbara Zoo, Oregon Zoo, Utah Zoo, (USA), and Chapultepec Zoo (Mexico) have actively participated in the breeding program to raise enough condors for the reintroduction program in both countries. Zoos implemented modifications in the management of condors, based on their biology, to ensure survivability and breeding success in the wild after reintroductions (Wallace et al 2007). The success of zoo-born California Condors reintroduced into the wild, depends on adequate reproductive and management programs of this species, both of which take into account the biology of this highly endangered species (see Figure 3B).

Breeding success and cub survival have been intensively studied in large felids (cheetahs [Durant 2000]). Some species, such as giant pandas and elephants are difficult to breed in zoos; on the contrary, ring-tailed lemurs of Madagascar breed well in zoos, but are critically endangered in the wild. The absence of species-specific courtship and mating behaviour in "non-breeding European mink (Mustela lutreola) males" threatens the conservation goal to maintain the genetic heterozygosity of the ex situ population; from a practical point of view, behavioural indicators could be used as a potential screening method for identifying successful future breeders. Recently, Kneidinger et al (2018) found that one of the key elements of male courtship behaviour was the vocalization "clucking", essential for a breeding attempt to end with copulation.

Other species, for which adequate spaces at zoos are not available, will have to be conserved in the wild. Whatever the result of these controversies is, we must pursue advances to establish efficient indicators that take into account the biological needs of each species to ensure better welfare while in human care. We must establish and/or update husbandry standards for each species and, as a consequence, develop coherent legal frameworks to guarantee wild animal welfare in zoos.

\section{Zoo animals' welfare assessment}

Over 80 years ago, the quality of life in zoo animals was already being questioned (Gillespie 1934). The visitors' attitude towards zoo animals has at times been negative because wild animals in certain facilities could be neglected or subjected to harsh human intervention. Besides, some management practices may alter physiological parameters, generate abnormal repetitive behaviours, and could have important negative consequences on growth and reproduction during the entire life of the animals (Clubb and Mason 2003; Clubb and Mason 2007; Morgan and Tromborg 2007). The "Five Freedoms" paradigm, developed more than 50 years ago, facilitated adequate welfare standards in the agriculture industry. Later on, the zoo community adopted it and proposed additional freedoms including the freedom of boredom and freedom of an animal to exert control over its quality of life. The Five Freedoms concept is limited and it does not measure welfare, but it gives structure and context to the main issues of wild animal welfare. (Kagan and Veasey 2013). Recently, the World Association of Zoos and Aquariums published the World Zoo and Aquarium Animal Welfare Strategy. This document guides the establishment and maintenance of acceptable animal welfare standards and related best practice through different policies including the use of the "Five Domains" model (including four physical/functional domains - nutrition, environment, physical health and behaviour - and one mental domain) to understand and assess animal welfare and to implement science-based animal welfare monitoring processes that use indices aligned with the animals' physical/functional states and behavioural activities (Mellor et al 2015).

Assessment of animal welfare in zoological collections should not only be restricted to vertebrates anymore. The welfare of insects, either for display or to be used as feed or enrichment is coming under scrutinity in zoos because of a generalized decline of insect species. It has been postulated that zoos have an ethical responsibility to consider insect welfare and to take into account behavioural responses and even cognitive functions of many invertebrate species for zoos to avoid sending a mixed message (of caring only for a certain type of animals' welfare). Although assessing animal welfare in insects kept ex-situ is in its early stages and no 
consensus has been reached, this issue has already extended to regulatory agencies in the Netherlands (Dutch Animal Act) and it is expected that other countries will follow these regulations regarding invertebrate species (Boppre et al 2019). Thus, the need for animal welfare assessment is constant. Current methods for assessing zoo animals' welfare in a non-invasive fashion trying to diminish stress in the animals while monitoring their welfare status are described in this section. A more comprehensive review on different methods and approaches including welfare epidemiology had been analyzed in Whitham and Wielebnowski (Whitham and Wielebnowski 2013) and Meehan et al (2016)'s reviews.

\subsection{Assessing physical health}

Physical health is an indicator of welfare, since minimizing disease and injury promotes comfort and functional capacity whilst reducing negative experiences such as pain, debility, and weakness (ZAAAW 2020). Hard-working zoologists understand the needs of their animals and provide the right food and care for them. When an animal gets sick, zoo veterinarians must use their knowledge to apply proper diagnostic techniques and treatment (see Figure $3 \mathrm{C}$ ). Health and welfare should be determined on an individual basis. Preventive medicine programs predominate over therapeutic measures due to the difficulties of early diagnosis of diseases and the handling and treatment of sick animals that can occasionally cause further deterioration. However preventative medicine, diagnostic, and therapeutic actions can be curtailed by the lack of resources destined for these actions. Although the field of zoo medicine has shown significant advances over the past two decades in developed nations with a direct and positive impact on animal welfare, these advances are not occurring in other geographic regions. A recent study showed that the state of zoological medicine in Latin-America is not satisfactory and that zoos should invest resources in this area to meet international standards for animal care and animal welfare (Riva et al 2019).

The use of the radio frequency identification (RFID) technology allows for continuous, reliable data collection that can provide valuable insight regarding the quantifiable relationship between animal behaviour, environment, and overall health (e.g. little blue penguin, [Kalafut and Kinley 2020]).

Many zoos and sanctuaries provide lifetime care for rescued, abused, unwanted or discarded animals; however, some zoos also help to rehabilitate wildlife and take in exotic pets that people no longer want or are no longer able to care for (see Figure 3D). Physical impairment has been shown to impede locomotion, foraging, social interaction, enrichment use, and enclosure utilization across a variety of species, quantifying the influence of disability on behaviour is important for understanding the impact on welfare (e.g. blinded brown bear (Ursus arctos arctos), confiscated amputated Malayan sun bears, Lewis et al [2017]).

Besides, body condition and weight changes are valuable measures that may indicate underlying health or welfare issues. An example is provided by body condition measured in Asian elephants (Kumar et al 2014).

\subsection{Assessing biological functioning}

Assessment of biological function is generally approached through the measurement of physiological responses indicative of stress, such as glucocorticoids (see below) as well as the incidence and severity of injury and disease. In this sense, an epidemiological approach is gaining venue (eg. Carlstead et al [2013]).

Stress and anxiety are generally undesirable states for zoo animals (Wielebnowski 2003); the main consequence of HPA axis activation is the release of glucocorticoid (GC) hormones, with measurement of GC metabolites in scats being an accepted method for the non-invasive evaluation of adrenocortical response to stressors in carnivores (in wolves (Canis lupus) [Young et al 2004; Barja et al 2008; Pifarre et al 2012; Escobar-Ibarra et al 2017]; polar bears (Shepherdson et al 2013); African wild dogs (Lycaon pictus) [van der Weyde et al 2016]; Royal Bengal tigers and Indian leopards, [Vaz et al 2017]), orangutans [Amrein et al 2014], marsupials (wallabies (Macropus eugenii) [McKenzie and Deane 2005]; wombats (Lasiorhinus latifrons) [Hogan et al 2011]; numbats (Myrmecobius fasciatus) [Hogan et al 2012]), white (Diceros bicornis) and black rhinos (Ceratotherium simum) [Carlstead and Brown 2005], and Asian elephants (Kumar et al 2014) among other animals.

High GC variability is considered an indicator of chronic or prolonged stress (Carlstead and Brown 2005). Wielebnowski et al (2002) found a positive relationship between pacing and corticoids in clouded leopards together with other variables that indicate reduced wellbeing. Clouded leopards kept in enclosures with more space have significantly lower fecal GC levels when compared to individuals housed in smaller enclosures. Similarly, felines housed close or visual distance from other predators have high levels of cortisol (Chosy et al 2014).

Researchers have long been interested in measuring stress responses in wild animals for a better understanding of the physiological impact of environmental variables and the potential management implications of human-induced stressors. The link between GC levels and well-being is not entirely clear, as some animals presenting behavioural changes associated with stress can also exhibit low levels of cortisol and vice-versa. A likely mediating effect of short-term elevations of GC on fitness should be further explored (McLeod et al 2018).

\subsection{Assessing mental health}

Improved welfare is possible when physical, social and psychological needs are met - the critical needs all animals have - including also exercise choice and control in their daily lives (Kagan and Veasey 2010). Perceived control refers to whether animals are aware of the choices and opportunities they have in their environment; choices and control that can be given through habitat design (as discussed 
in Section 2) as well as the use of technological aspects (Brando et al 2018).

The main claim to the moral justification for zoos and aquariums relies on the welfare of the animal species concerned, so one approach that characterizes the attempt to enhance zoo animal welfare through the achievement of optimal husbandry standards is the development of speciesspecific guidelines for zoo animals; they include how biological and behavioural needs of a species can be best met in the management of wild animals in human care (Barber and Lewis 2010). Maintaining a high standard of welfare for each animal - before, during, and after each animal visitor interaction - is difficult due to the diversity of animals involved; however, the World Association of Zoos and Aquariums (WAZA 2016), recommends the adoption of a policy to ensure that animal welfare is guaranteed at all times during the interactions. Several examples of frameworks for zoo animal welfare assessment are reviewed by Wolfensohn et al (2018).

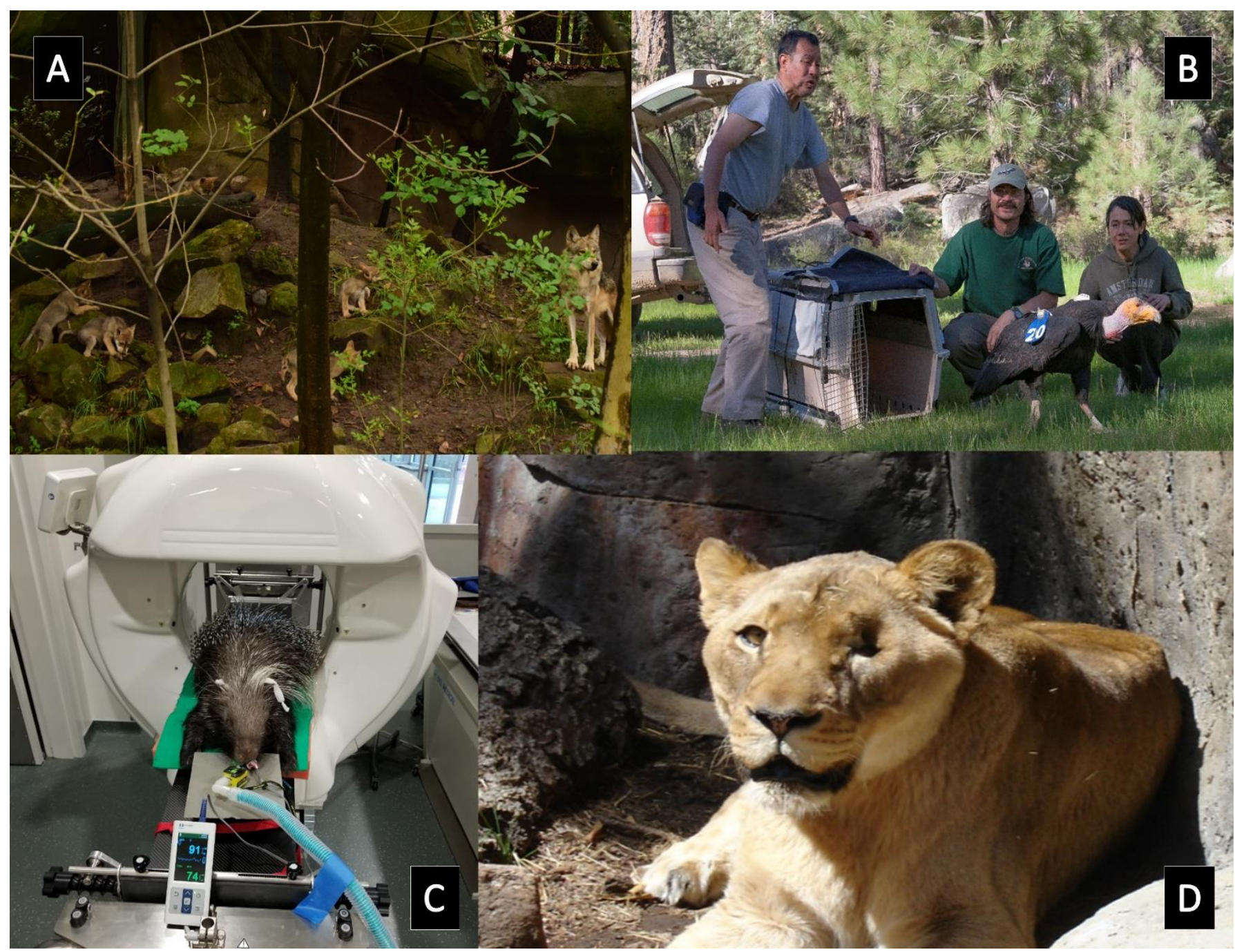

Figure 3 A. Breeding Mexican wolves in zoos has been essential for the conservation of this species. B. Reintroduction of zoo born Cal ifornia condors into the wild is a fundamental part of the conservation programme of this highly endangered species. C. Advanced diagnostic and therapeutic technologies should be available in zoos to ensure the health and welfare of wild animals in human care.D. Rescued lion showing signs of animal abuse. Photo credits A: A. Rodríguez / Chapultepec Zoo B: M.A. Sicilia / CONABIO C: C.R. Sánchez D: M. Alonso-Spilsbury.

Due to the poor public image stereotypies in animals convey in zoos (Miller 2012), these abnormal behaviours (see Section 4) are commonly used in welfare assessments. When assessing animal behaviour (Dawkins 2003) systematic data collection is traditionally preferred over keeper surveys because it is more objective, can be collected across different times/seasons/environments, and is a quantitative form of measurement (Crockett 1996). However, keeper surveys are proving to be a simple way to collect data, they can increase sample size and facilitate multi-institutional studies (Less et al 2012); moreover, staff members are reliable, credible, and valuable sources of welfare data (Whitham and Wielebnowski 2009). Besides, keeper knowledge can provide valuable insight into the characteristics of individual animals (eg. African elephant (Loxodonta africana) [Grand et al 2012] and chimp welfare, happiness, and personality [Robinson et al 2017]). Furthermore, Yon et al (2019), recently showed that an evidence-based behavioural welfare assessment tool 
for use by animal caretakers can be developed within the constraints of zoo-based research, which could be applied to a range of wild species in human care.

On the other end of the spectrum, prosocial behaviours in social animals have also been studied (Crockford et al 2008). Good welfare not only entails freedom from lasting or severe pain, prolonged hunger, or other forms of suffering but also that the animals have opportunities for positive experiences, such as pleasure or excitement or the freedom to perform natural behaviours (Wolfensonhn et al 2018) and play. In recent years, there has been an improvement in researchers' ability to evaluate zoo animals feelings and emotions or 'affective states', particularly positive states -crucial elements of good welfare (see review by Yeates \& Main [2008]) - to improve their quality of life by providing them with rewarding experiences (e.g. Mellor [2015]). Exploratory behaviour, affiliative behaviour, vocalizations, facial expressions, anticipatory behaviour, and play have all been used for the assessment and monitoring of positive emotions. Mellor and Beausoleil (2015) state that positive welfare states are promoted either when essential needs had been addressed before employing enrichment strategies, or by providing a stimulus-enriched environment to animals. A pilot study aimed at exploring the use of qualitative behaviour assessment (QBA) was conducted to address HAR in zoo-housed giraffes (Patel et al 2019). Furthermore, infrared thermography (IRT) has shown some promise in the assessment of emotions in the gorilla (Heintz et al 2019).

Temperament particularly emphasizes the way individuals react to environmental change and challenge and presents a more comprehensive view of an individual's behaviour (Shepherdson et al 2013). Zoo animal personality is being increasingly investigated in several species, including chimpanzees, black rhinoceros, cheetahs, and giant pandas (Tetley and O'Hara 2012). Personality rating systems have been developed for gorillas (Gold and Maple 1994), orangutans (Pongo pygmaeus and P. abelii; [Weiss et al 2006; Weiss et al 2011]), chimpanzees (Robinson et al 2017), polar bears (Shepherdson et al 2013), felids (Phillips et al 2017), and wild (Lee and Moss 2012) and zoo African elephants (Grand et al 2012). As an example, three emotional state domains had been identified in big cats, apparently associated with "nervousness," "adventurousness" and "aggression" (Phillips et al 2017). Individual animals in modern zoos are expected not only to thrive but also to lead long, high-quality lives while serving as conservation ambassadors for their wild counterparts (Meehan et al 2016).

\section{Conservation and Animal Welfare}

Nowadays, public concern regarding the use and management of domestic and wild animals that leads to great support of animal rights and welfare organizations is growing. At the same time, there is strong support for the conservation of endangered species. Both animal rights and conservation concepts are ethical perspectives, and it is important to consider that the concept of animal rights differ from the concept of animal welfare (Hutchins 2007). Some authors have argued that the emphasis on individual welfare is antiethical to the conservation of species and could lead to a conflict between the individual and population welfare (Conway 1976). Other authors have discussed that wild animal conservation and animal welfare represent two different points of view out of the same aspect. Assuming that the goal of conservation is to maintain free-ranging and self-sustaining wildlife populations, thus conservation efforts must focus on sustaining the natural environment while meeting human needs. Similarly, the goal of animal welfare is to sustain a quality of life for all species. In conservation science, sometimes the interests of individuals are traded off against perceived benefits to higher levels of the organization including populations, species, and ecosystems.

Many biologists and conservationists value both the welfare of individual animals and the well-being of populations, species, and ecosystems, but on most occasions, the conservation of species and populations surpasses all other values, including the welfare of individuals, so there is a perception that animal welfare and conservation are incompatible (Paquet and Darimont 2010). Sometimes, the animal rights and the conservation ethics may lead to the same considerations: both will oppose to the destruction of wildlife habitat, and both ethics favor saving threatened or endangered species or populations, but they will disagree when the animal rights of sentient individuals come into conflict with the conservation of populations, species, habitats, and ecosystems. Animal rights advocates represent a narrow view of nature, focusing their attention on individual animals, and implying that species and ecosystems can be saved by preserving their parts and leaving nature alone. Ecologists, in contrast, show us that there are complex relations between species in functioning ecosystems. Therefore, at this point in history, there is a need for human intervention and carefully planned management to avoid the loss of biological diversity (Hutchins 2007). The animal rights ethics generally opposes wild animals in zoos, even under the best conditions; in this view, individual animals have the right to freedom. Nevertheless, the Mexican wolf, the blackfooted ferret, the California condor, and many other species could be extinct without the implementation of ex situ conservation programmes, including activities such as breeding and reintroduction of these species using zoo born individuals.

Frequently, zoos must confront the dilemma of helping rescued or confiscated individual animals, and in the process using invaluable space that could be used to support endangered species conservation programs (Kagan and Veasey 2010). At this point, it is important to remember that ethics and animal welfare is one of the main tools to develop the concept of Integrated Conservation (WAZA 2005; Barongi et al 2015). Most days to day activities in zoos focus on animal health and adequate management, so one of the main concerns of perhaps all of the professionals that work in zoos is animal welfare. In the past few years, compassionate 
conservation has emerged as a new approach, proposing that conservation and animal welfare should be considered jointly; it also addresses topics of animal welfare in field conservation, zoo animal welfare and conservation, international trade in live animals, and the conservation impacts of wildlife rescue, rehabilitation, and release. Zoos must deal with criticism and change their practices to meet higher standards in animal care and management (Bekoff 2013; Gray 2017; Gray 2018). Zoos over the world have to rethink their future and start to work in founding a "new zoo" concept, through a change of paradigms (Baschetto 2019). If we care for the future of life in our planet, zoos must also play an important role to make conservation their highest priority, and educate visitors about the reality of the loss of diversity in wild spaces. Zoos must promote conservation and work to secure wild places and habitats for wild animals. These institutions must outgrow their past, based in awareness and entertainment, and become real conservation organisations that demonstrate compassion for all living beings (Hutchins 207; Gray 2017).

\section{Final Considerations}

Our understanding of what zoos are and what we want them to be - entertainment destinations or education, science, and conservation centres - is evolving. While a lot of people still visit zoos primarily for entertainment, the benefits they provide both to animals and to us make them worthwhile.

There is a need to integrate animal welfare into exhibit designs, including complexity, choice, and control. The naturalisation of zoos should be compulsory.

Zoos constitute an invaluable resource for wildlife conservation. In some cases, they are the only hope for critically endangered species including those that have become extinct in the wild. Zoos should not only support conservation projects, these institutions should become conservation organizations using zoos as one of their tools.

Zoos are actively involved in science and research activities, which contribute to evidence-informed management and conservation actions. The physical state, biological function, and mental state of the animals should be measured as welfare indicators.

Zoos also offer formal and informal, educational opportunities aimed towards raising awareness and supporting conservation.

We must keep in mind that the most important assets of zoos are the populations of wild animals they keep. Thus, animal welfare becomes a priority: zoos must meet higher standards of animal husbandry, veterinary care, management, and exhibit/facilities design to comply with their mission and pursue compassionate conservation.

Perhaps the discussion should now focus on which species are suitable for management in human care, as demonstrated by scientific data concerning health, welfare, and successful reproduction, all essential to maintaining long term viable ex situ populations that allow zoos to pursue their ultimate goal: conservation.

\section{Conflict of Interest}

The authors declare that there are no conflict of interest with this work.

\section{Funding}

This research did not receive any financial support.

\section{References}

Altman JD (1998) Animal activity and visitor learning at the zoo. Anthrozoos 11:2-21.

Amrein M, Heistermann M, Weingrill T (2014) The effect of fission-fusion zoo housing on hormonal and behavioral indicators of stress in Bornean orangutans (Pongo pygmaeus). International Journal of Primatology 35:50928.

Arias BF (2011) Animal welfare, a bioethical principle to consider in wildlife conservation in zoos. In: Escobar TJ (ed) Proposals and Reflections to Support Bioethics Education. Colección Bios y Ethos. Editorial del Bosque, Bogota, pp 235-63.

Arlettaz R, Schaub M, Fournier J, Reichlin TS, Sierro A, Watson JEM, Braunisch $V(2010)$ From publications to public actions: When conservation biologists bridge the gap between research and implementation. BioScience 60:835842 .

Baker K (2004) Benefits of positive human interaction for socially housed chimpanzees. Animal Welfare 13:239-45.

Barber J, Lewis D, Agoramoorthy G, Stevenson MF (2010) Setting standards for evaluation of captive facilities. In: Kleiman D, Thompson K, Baer K (eds) Wild Mammals in Captivity: Principles and Techniques for Zoo Management 2nd ed. University of Chicago Press, Chicago, pp 22-34.

Barja I, Silván G, Illera JC (2008) Relationships between sex and stress hormone levels in feces and marking behavior in a wild population of Iberian wolves (Canis lupus signatus). Journal of Chemical Ecology 34:697-701.

Barongi R, Fisken FA, Parker M, Gusset M (2015) Committing to Conservation: The World Zoo and Aquarium Conservation Strategy. Gland: WAZA Executive Office. WAZA, USA.

Baschetto F (2019) Zoos: society and paradigms. In: Fernandez C (ed) Embassies of Nature. Zoos, Aquariums and Oceanariums of Argentina in the 21st Century. Vazquez Mazzini Editores, Buenos Aires, pp 23- 71.

Bechert US, Brown JL, Dierenfeld ES, Ling PD, Molter CM, Schulte BA (2019) Zoo elephant research: contirbutions to conservation of captive and freeranging species. International Zoo Yearbook 53:1-27.

Bekoff M (2013) Ignoring Nature no More: The Case for Compassionate Conservation. University of Chicago Press, USA.

Bertschinger HJ, Meltzer DGA, van Dyk A (2008) Captive breeding of cheetahs in South Africa: 30 years of data from the de Wildt cheetah and wildlife centre. Reproduction in Domestic Animals 43 (Suppl):66-73.

Bonnie KE, Ang MYL, Ross SR (2016) Effects of crowd size on exhibit use by and behavior of chimpanzees (Pan troglodytes) and Western lowland gorillas (Gorilla gorilla) at a zoo. Applied Animal Behaviour Science 178:102-10.

Boppre M, Vane-Wright RI (2019) Welfare Dilemmas Created by Keeping Insects in Captivity. In: Carere C, Mather J (eds) The Welfare of Invertebrate Animals. Springer Nature, Switzerland, pp 23-67.

Brando S, Broom DM, Acasuso-Rivero C, Clark F (2018) Optimal marine mammal welfare under human care: Current efforts and future directions. Behavioural Processes 156:16-36.

Breton G, Barrot S (2014) Influence of enclosure size on the distances covered and paced by captive tigers (Panthera tigris). Applied Animal Behaviour Science 154:66-75.

Broom DM (1983) Stereotypies as animal welfare indicators. Current Topics in Veterinary Medicine and Animal Science 23:81-87. 
Brummer SP, Gese EM, Shivik JA (2010) The effect of enclosure type on the behavior and heart rate of captive coyotes. Applied Animal Behaviour Science 125:171-80.

Byers O, Lees C, Wicken J, Schwitzer C (2013) The One Plan Approach: The Philosophy and Implementation of CBSG's Approach to Integrated Species Conservation Planning. WAZA Magazine, Towards Integrated Species Conservation 14: 2-5.

Carder G, Semple S (2008) Visitor effects on anxiety in two captive groups of western lowland gorillas. Applied Animal Behaviour Science 115:211-20.

Carlstead K, Brown JL (2005) Relationships between patterns of feacal corticoid excretion and behavior, reproduction, and environmental factors in captive black (Diceros bicornis) and white (Ceratotherium simum) rhinoceros. Zoo Biology 24:215-32.

Carlstead K, Mench JA, Meehan C, Brown JL (2013) An epidemiological approach to welfare research in zoos: The elephant welfare project. Journal of Applied Animal Welfare Science 16:319-37.

Chamove AS, Hosey G, Schaetzel P (1988) Visitors excite primates in zoos. Zoo Biology 7:359-69.

Chelluri GI, Ross SR, Wagner KE (2013) Behavioral correlates and welfare implications of informal interactions between caretakers and zoo-housed chimpanzees and gorillas. Applied Animal Behaviour Science 147:306-15.

Chosy J, Wilson M, Santymire R (2014) Behavioral and physiological responses in felids to exhibit construction. Zoo Biology 33:267-74.

Claxton AM (2011) The potential of the human-animal relationship as an environmental enrichment for the welfare of zoo-housed animals. Applied Animal Behaviour Science 133:1-10.

Clayton S (2016) Learning to care about animal conservation. Center for Humans and Nature, Expanding our Natural \& Civic Imagination. https://www.humansandnature.org/learning-to-care-about-animalconservation. Accessed on: February 15, 2016.

Clubb R, Mason G (2007) Natural behavioural biology as a risk factor in carnivore welfare: how analysing species differences could help zoos improve enclosures. Applied Animal Behaviour Science 102:303-28.

Clubb R, Mason, G (2003) Captivity effects on wide-raging carnivores. Nature 425:473-474

Coe J, Dykstra G (2010) New and sustainable directions in zoo exhibit design. In: Kleiman D, Thompson K, Baer K (eds) Wild Mammals in Captivity: Principles and Techniques for Zoo Management 2nd ed. University of Chicago Press, Chicago, pp 202-215.

Conde DA, Flesness N, Colchero F, Jones OR, Scheuerlein AA (2011) An emerging role of zoos to conserve biodiversity. Science 331:1390-1391.

Conway WG (1976) The surplus problem. In Wheeling WV (ed) AAZPA National Conference. American Association of Zoological Parks and Aquariums, pp 20-24.

Crockett C (1996) Data collection in the zoo setting, emphasizing behavior. In: Harris H, Kleiman D, Allen M, Thompson K, Lumpkin S (eds) Wild Mammals in Captivity. The University of Chicago Press, Chicago, pp 545-65.

Crockford C, Wittig RM, Whitten PL, Seyfarth RA, Cheney DL (2008) Social stressors and coping mechanisms in wild female baboons (Papio hamadryas ursinus). Hormones and Behavior 53:254-65.

Davey G (2007) Public perceptions in urban China towards zoos and their animal welfare. Human Dimensions of Wildlife 12:367-74.

Dawkins MS (2003). Behaviour as a tool in the assessment of animal welfare. Zoology 106:383-87.

de Azevedo CS, Lima MF, da Silva VC, Young RJ, Rodrigues M (2012) Visitor influence on the behavior of captive greater rheas (Rhea americana, Rheidae Aves). Journal of Applied Animal Welfare Science 15:113-25

Descovich KA, Lisle AT, Johnston S, Phillips CJC (2012) Space allowance and the behaviour of captive southern hairy-nosed wombats (Lasiorhinus latifrons). Applied Animal Behaviour Science 140:92-98.

Durant SM (2000) Predator avoidance, breeding experience and reproductive success in endangered cheetahs, Acinonyx jubatus. Animal Behaviour 60:121-30.

Eltorai AEM, Sussman RW (2010) The visitor effect and captive black-tailed prairie dog behavior. Zoologische Garten 79:109-20.

Escobar-Ibarra I, Mayagoitia-Novales L, Alcántara-Barrera A, Cerda-Molina AL, Mondragón-Ceballos R, Ramírez-Necoechea R, Alonso-Spilsbury $M$ (2017) Long-term quantification of faecal glucocorticoid metabolite concentrations reveals that Mexican gray wolves may habituate to captivity. The European Zoological Journal 84:311-20.

Falk JH (2005) Free-choice environmental learning: framing the discussion. Environmental Education Research 11:265-80.

Fernández-Juricic E, Schulte BA (2016) Conservation behavior: continued application, development and expansion. Animal Behaviour 120:195-96.

Fox MW (1968) Abnormal behavior in animals. Philadelphia, USA

Garner JP (2005) Stereotypies and other abnormal repetitive behaviours: potential impact on viability reliability, and replicability of scientific outcomes. Institute for Laboratory Animal Research Journal 42:106-17.

Gillespie TH (1934) Is it cruel? A study of the condition of captive and performing animals. Herbert Jenkins, London.

Gold KC, Maple TL (1994) Personality assessment in the gorilla and its utility as a management tool. Zoo Biology 13:509-22.

Goswami S, Tyagi PC, Malik PK, Pandit SJ, Kadivar RF, Fitzpatrick M, Mondol $S$ (2020) Effects of personality and rearing-history on the welfare of captive Asiatic lions (Panthera leo persica). PeerJournal 8:e8425.

Grand AP, Kuhar CW, Leighty KA, Bettinger TL, Laudenslager ML (2012) Using personality ratings and cortisol to characterize individual differences in African Elephants (Loxodonta africana). Applied Animal Behaviour Science 142: 69-75.

Gray J (2017) Zoo Ethics. The Challenges of Compassionate Conservation. CSIRO Publishing. Clayton South, Australia.

Gray J (2018) Challenges of compassionate conservation. Journal of Applied Animal Welfare Science 21(Sppl):34-42.

Gross M (2012) Felids fighting for survival. Current Biology 22:R993-R895.

Gusset M, Dick G (2012) Editorial. Fighting extinction. World Association of Zoos and Aquariums Magazine 13:1-2.

Heintz MR, Fuller G, Allard S (2019) Exploratory Investigation of Infrared Thermography for Measuring Gorilla Emotional Responses to Interactions with Familiar Humans. Animals 9:604.

Hoffmann M, Hilton-Taylor C, Angulo A, Böhm M, Brooks TM, Butchart SHM (2010) The Impact of Conservation on the Status of the World's Vertebrates. Science 330:1503-1509.

Hogan LA, Johnston, SD, Lisle TA, Keeley T, Wong P, Nicolson V, Horsup AB, Janssen T (2011) Behavioural and physiological responses of captive wombats (Lasiorhinus latifrons) to regular handling by humans. Applied Animal Behaviour Science 134:217-28.

Hogan LA, Lisle AT, Johnston SD, Robertson H (2012) Non-invasive assessment of stress in captive numbats, Myrmecobius fasciatus (Mammalia: Marsupialia), using faecal cortisol measurement. General and Comparative Endocrinology 179:376-83.

Hopper L (2017) Cognitive research in zoos. Current Opinion in Behavioral Sciences 16:100-110.

Horback KM, Miller L, Andrews J, Kuczaj SA, Anderson M (2012) The effects of GPS collars on African elephant (Loxodonta africana) behavior at the San Diego Zoo Safari Park. Applied Animal Behaviour Science 142:76-81.

Hosey G (2000) Zoo animals and their audiences: what is the visitor effect? Animal Welfare 9:343-57.

Hosey G, Melfi V (2015) Are we ignoring neutral and negative human-animal relationships in zoos?. Zoo Biology 34:1-8.

Hosey GA (2008) Preliminary model of human-animal relationships in the zoo. Applied Animal Behaviour Science 109:105-27.

Hutchins M (2001) Conservation fieldwork. In: Bell CE (Ed) Encyclopedia of the World's Zoos, Fitzroy Dearborn Publishers, Chicago, pp 299 - 303.

Hutchins M (2007) The animal rights - conservation debate: can zoos and aquariums play a role? In: Zimmermann A, Hatchwell M, Dickie L, West $C$ (eds) Zoos in the $21^{\text {st }}$ Century. Cambridge University Press, Cambridge, pp 92-109. 
IUDZG/CBSG (IUCN/SSC) (1993) Executive Summary, The World Zoo Conservation Strategy; The Role of the Zoos and Aquaria of the World in Global Conservation, Chicago Zoological Society, USA.

Jackson DW (1990) Landscaping in hostile environments. International Zoo Yearkbook 29:10-15.

Kagan R, Allard S, Carter S (2018) What is the future for zoos and aquariums? Journal of Applied Animal Welfare Science 21(Suppl): 59-70.

Kagan R, Carter S, Allard S (2015) An universal welfare framework for zoos. Journal of Applied Animal Welfare Science 18:S1-S10.

Kagan R, Veasey J 2010 Challenges of zoo animal welfare. In: Kleiman D, Thompson K, Baer K (eds) Wild Mammals in Captivity: Principles and Techniques for Zoo Management, 2nd ed. University of Chicago Press, Chicago, pp 11-21.

Kalafut K, Kinley R (2020) Using radio frequency identification for behavioral monitoring in little blue penguins. Journal of Applied Animal Welfare Science 23:62-73.

Karanikola P, Tampakis S, Tsantopoulos G, Digbasani C (2014) The public zoo as recreation and environmental education area: Visitor's perceptions and management implications. WSEAS Transactions on Environment and Development 10:81-91.

Kelly KR, Harrison ML, Size DD, MacDonald, SE (2015) Individual effects of seasonal changes, visitor density, and concurrent bear behavior on stereotypical behaviors in captive polar bears (Ursus maritimus). Journal of Applied Animal Welfare Science 18:17-31.

Keulartz J (2015) Captivity for conservation? Zoos at a crossroads. Journal of Agricultural and Environmental Ethic 28:335-51.

Kneidinger N, Nagl A, Kiik K, Schwarzenberger F, Maran T (2018) The individual courtship behaviour of male European mink (Mustela lutreola) is a good indicator for their breeding success. Applied Animal Behaviour Science 205:98-106.

Kuar CW (2008) Group differences in captive gorillas' reaction to large crowds. Applied Animal Behaviour Science 110:377-385

Kumar V, Reddy VP, Kokkiligadda A, Shivaji S, Umapathy G (2014) Noninvasive assessment of reproductive status and stress in captive Asian elephants in three south Indian zoos. General and Comparative Endocrinology 201:37-44.

Ladeia DLM, Young RJ (2015) Can enrichment make Brazilian tapir spend more time on view to the public?. Journal of Applied Animal Welfare Science 18:74-81.

Larsen MJ, Sherwen SL, Rault JL (2014) Number of nearby visitors and noise level affect vigilance in captive koalas. Applied Animal Behaviour Science 154:76-82.

Lascuráin M, List R, Barraza L, Díaz PE, Gual SF, Maunder M, Dorantes J, Luna VE (2009) Ex situ conservation. In: Capital Natural de México Vol. II. Estado de Conservación y Tendencias de Cambio. CONABIO, México, pp 517-44

Laule G, Desmond T (1998) Positive reinforcement training as an enrichment strategy. In: Shepherdson D, Mellen JD, Hutchins M (eds) Second Nature: Environmental Enrichment for Captive Animals. Smithsonian Institution Press, Washington, pp 302-13.

Lee HS (2015) Measurement of visitors' satisfaction with public zoos in Korea using importance-performance analysis. Tourism Management 47:251-60.

Lee PC, Moss CJ (2012) Wild female African elephants (Loxodonta africana) exhibit personality traits of leadership and social integrations. Journal of Comparative Psychology 126:224-32.

Less EH, Kuhar CW, Dennis PM, Lukas KE (2012) Assessing inactivity in zoo gorillas using keeper ratings and behavioral data. Applied Animal Behaviour Science 137:74-79.

Lewis K, Deskovich K, Jones M (2017) Enclosure utilisation and activity budgets of disabled Malayan sun bears (Helarctos malayanus). Behavioural Processes 145:65-72.

Li C, Juang Z, Tang S. Zeng Y (2007) Evidence of effects of human disturbance on alert response in Pere David's deer (Elephurus davidaneus). Zoo Biology 26:461-70.

Lindblom E (2014) The effect of visual barriers, outdoor housing and feeding enrichment on the behaviour of drills (Mandrillus leucophaeus) at Parken
Zoo. Master's thesis, Linkőpings Universitet, Linkőping, Sweden.

List R (2005) Canis lupus. In: Ceballos G, Oliva G (eds) The Wild Mammals of Mexico. CONABIO-Fondo de Cultura Económica, México, pp 350-53

Loh TL, Larson ER, David SR, de Souza LS, Gericke R, Gryzbek M, Kough AS, Willink PW, Knapp CR (2018) Quantifying the contribution of zoos and aquariums to peer-reviewed scientific research. FACETS 3:287-299.

Lundin L (2013). Visitor effects on the behavior of drills (Mandrillus leucophaeus) and petting zoo animals at Parken Zoo. Master Thesis, Linkőpings Universitet. Linkőping, Sweden.

Majchrzak YN, Mastromonaco GF, Korver W, Burness G (2015) Use of salivary cortisol to evaluate the influence of rides in dromedary camels. General and Comparative Endocrinology 211:123-30.

Mallapur A, Chellam R (2002) Environmental influences on the activity budget of leopards (Panthera pardus) in four zoos in southern India. Journal of Applied Animal Welfare Science 5:111-24.

Mallapur A, Sinha A, Waran N (2005) Influence of visitor presence on the behaviour of captive lion-tailed macaques (Macaca silenus) housed in Indian zoos. Applied Animal Behaviour Science 94:341-52.

Maple TL, Bashaw MJ (2010) Research trends in zoos. In: Kleiman D, Thompson K, Baer K (eds) Wild Mammals in Captivity: Principles and Techniques for Zoo Management, 2nd ed. University of Chicago Press, Chicago, pp 288-300.

Margulis SW, Hoyos CH, Anderson M (2003) Effect of felid activity on zoo visitor interest. Zoo Biology 22:587-99.

Marzluff JM, Swift KN (2017) Connecting animal and human cognition to conservation. Current Opinion in Behavioral Sciences 16:87-92.

Mason GJ (1991) Stereotypies: a critical review. Animal Behaviour 41:101537.

Mason GJ (2010) Species differences in responses to captivity: stress, welfare and the comparative method. Trends Ecology Evolutions 25:718-21.

Mason GJ, Latham N (2004) Can't stop, won't stop: is stereotypy a reliable animal welfare indicator? Animal Welfare 13:S57-S69.

Mason GJ, Veasey JS (2010) How should the psychological well-being of zoo elephants be objectively investigated? Zoo Biology 29:237-55.

McGrath N, Walker J, Nilsson D, Phillips C (2013) Public attitudes towards grief in animals. Animal Welfare 22:33-47.

McKenzie S, Deane EM (2005) Faecal corticosteroid levels as an indicator of wellbeing in the tammar wallaby, Macropus eugenii. Comparative Biochemistry and Physiology-Part A 140:81-87.

McLeod KJ, Sheriff MJ, Ensminger DC, Owen DAS, Langkilde T (2018) Survival and reproductive costs of repeated acute glucocorticoid elevations in a captive, wild animal. General and Comparative Endocrinology 268:1-6.

Mcphee ME, Carlstead K (2010) The importance of maintaining natural behaviors in captive mammals. In: Kleiman D, Thompson K, Baer K (eds) Wild Mammals in Captivity: Principles and Techniques for Zoo Management 2nd ed. University of Chicago Press, Chicago, pp 303-13.

Meehan CL, Mench JA, Carlstead K, Hogan JN (2016) Determining connections between the daily lives of zoo elephants and their welfare: An epidemiological approach. PlosOne 11(7):e0158124.

Mellor D, Beausoleil N (2015) Extending the 'five domains' model for animal welfare assessment to incorporate positive welfare states. Animal Welfare 24:241-53.

Mellor DJ (2015) Enhancing animal welfare by creating opportunities for positive affective engagement. New Zealand Veterinary Journal 63:3-8.

Mellor DJ, Hunt S, Gusset M (2015) Caring for Wildlife: The World Zoo and Aquarium Animal Welfare Strategy. WAZA Executive Office, Gland.

Miller CS, Hebblewhite M, Petrunenko YK, Seryodkin IV, Goodrich JM, Miquelle DG (2014) Amur tiger (Panthera tigris altaica) energetic requirements: Implications for conserving wild tigers. Biological Conservation 170:120-29.

Miller L, Tobey JR 2012 Regurgitation and reingestion in bonobos (Pan paniscus): Relationships between abnormal and social behavior. Applied Animal Behaviour Science 141:65-70.

Miller LJ (2012) Visitor reaction to pacing behavior: Influence on the 
perception of animal care and interest in supporting zoological institutions. Zoo Biology 31:242-48.

Mohapatra RK, Panda S, Acharya UR (2014) Study on activity pattern and incidence of stereotypic behavior in captive tigers. Journal of Veterinary Behavior: Clinical Applications and Research 9:172-176.

Montaudouin S, Pape G (2004) Comparison of the behaviour of European brown bears (Ursus arctos arctos) in six different parks, with particular attention to stereotypies. Behavioural Processes 67(2):235-44.

Montenha JC, Silva SL, Boere, V (2009) Comparison of salivary cortisol concentrations in jaguars kept in captivity with differences in exposure to the public. Ciencia Rural 9:1745-51.

Mooney A, Conde DA, Healy K, Buckley YM (2020) A system wide approach to managing zoo collections for visitor attendance and in situ conservation. Nature Communications 11:584.

Moreira N, Brown JL, Moraes W, Swanson WF, Monteiro-Filho ELA (2007) Effect of housing and environmental enrichment on adrenocortical activity, behaviour and reproductive cyclicity in the female tigrina (Leopardus tigrinus) and margay (Leopardus wiedii). Zoo Biology 26:441-60.

Morgan KN, Tromborg CT (2007) Sources of stress in captivity. Applied Animal Behaviour Science 102:262-302.

Nygren NV, Ojalammi S (2018) Conservation education in zoos: A literature review. Finnish Journal for Human-Animal Studies 4:62-76.

O'Donovan D, Hindle JE, McKeown S, O'Donovan S (1993) Effect of visitors on the behaviour of female cheetahs. International Zoo Yearbook 32:238-44.

Owen C. (2004). Do visitors affect Asian short-clawed otter (Ambionyx cinerea) in a captive environment?. Proceedings $6^{\text {th }}$ Annual Symposium on Zoo Research. UK, Edinburgh, pp 202-211.

Palmer C, Sandøe P (2016) How to care while conserving zoo animals. Center for Humans and Nature, Expanding our Natural \& Civic Imagination. July 2016. https://www.humansandnature.org/how-to-care-while-conservingzoo-animals. Accessed on: October 2, 2018.

Paquet PC, Darimont CT (2010) Wildlife conservation and animal welfare: two sides of the same coin? Animal Welfare 19:177-190.

Patel F, Wemelsfelder F, Ward SJ (2019) Using qualitative behaviour assessment to investigate human-animal relationships in zoo-housed giraffes (Giraffa camelopardalis). Animals 9:381.

Patel F, Whitehouse-Tedd K, Ward SJ (2019) Redefining human-animal relationships: An evaluation of methods to allow their empirical measurement in zoos. Animal Welfare 28:247-59.

Pearson EL, Lowry L, Dorrian J, Litchfield CA (2014) Evaluating the conservation impact of an innovative zoo-based educational campaign: 'Don't palm us off' for orang-utan conservation. Zoo Biology 33:184-96.

Phillips CJC, Tribe A, Lisle A, Galloway TK, Hansen K (2017) Keepers' rating of emotions in captive big cats, and their use in determining responses to different types of enrichment. Journal of Veterinary Behavior 20:22-30.

Pifarre M, Valdez R, González-Rebeles C, Vázquez C, Romano M, Galindo F (2012) The effect of zoo visitors on the behaviour and faecal cortisol of the Mexican Wolf (Canis lupus baileyi). Applied Animal Behaviour Science 136:57-62.

Polanco A, Díez-León M, Mason G (2018) Stereotypic behaviours are heterogeneous in their triggers and treatments in the American mink, Neovison vison, a model carnivore. Animal Behaviour 141:105-14.

Pomerantz O, Meiri S, Terkel J (2013) Socio-ecological factors correlate with levels of stereotypic behavior in zoo-housed primates. Behavioural Processes 98:85-91

Pomerantz O, Paukner A, Terkel J (2012) Some stereotypic behaviours in rhesus macaques (Macaca mulatta) are correlated with both perseveration and the ability to cope with acute stressors. Behavioural Brain Research 230:274-80.

Puan CL, Zakariz M (2007) Perception of visitors towards the role of zoos: a Malasyan perspective. International Zoo Yearbook 41:226-32.

Quadros S, Goulart VDL, Passos L, Vecci MAM, Young RJ (2014) Zoo visitor effect on mammal behaviour: Does noise matter? Applied Animal Behaviour Science 156:78-84.
Quirke T, O'Riordan RM, Zuur A (2012) Factors influencing the prevalence of stereotypical behaviour in captive cheetahs (Acinonyx jubatus). Applied Animal Behaviour Science 143:189-97.

Reade RS, Waran NK (1996) The modern zoo: How do people perceive zoo animals? Animal Welfare 47:109-18.

Riva HG, Zordan MA, Sanchez CR (2019) The Current State of Zoological Medicine in Zoos and Aquariums in Latin America. International Zoo Yearbook 54:1-17.

Robinson LM, Altschul DM, Wallace EK, Úbeda Y, Llorente M, Machanda Z, Slocombe KE, Leach MC, Waran NK Weiss A (2017) Chimpanzees with positive welfare are happier, extraverted, and emotionally stable. Applied Animal Behaviour Science 191:90-97.

Robson, C (2004) Do visitors and weather affect captive Asian elephant (Elephas maximus) behaviour?. Proceedings $6^{\text {th }}$ Annual Symposium on Zoo Research. UK, Edinburgh.

Roe K, McConney A (2015) Do zoo visitors come to learn? An internationally comparative, mixed-methods study. Environmental Education Research 1:865-84.

Safina C (2018) Where are zoos going, or are they gone? Journal of Applied Animal Welfare Science 21:4-11.

Saunders SP, Harris T, Traylor-Holzer K, Beck KG (2014) Factors influencing breeding success, ovarian cyclicity, and cub survival in zoo-managed tigers (Panthera tigris). Animal Reproduction Science 144:38-47.

Schultz JT, Young JK (2018) Behavioral and spatial responses of captive coyotes to human activity. Applied Animal Behaviour Science 205:83-88.

Scientific American (2009) How do zoos help endangered animals?. April 2009. https://www.scientificamerican.com/article/how-do-zoos-helpendangered-animals/. Accessed on: February 10, 2019.

Scott K (2014) Behaviour and endocrinology of meerkats in zoos. Doctoral Thesis, University of Exeter, England.

Sellinger RL, Ha JC 2005 The effects of visitor density and intensity on the behaviour of two captive jaguars (Panthera onca). Journal of Applied Animal Welfare Science 8:233-44.

Shepherdson D (1998) Tracing the path of environmental enrichment in zoos. In: Shepherdson D, Mellen JD, Hutchins M (eds) Environmental Enrichment for Captive Animals. Smithsonian Institution Press, Washington, pp 1-12.

Shepherdson D (2010) Principles of and research on environmental enrichment for mammals. In: Kleiman D, Thompson K, Baer K (eds) Wild Mammals in Captivity: Principles and Techniques for Zoo Management 2nd ed. University of Chicago Press, Chicago, pp 62-67.

Shepherdson D, Lewis KD, Carlstead K, Bauman J, Perrin N (2013) Individual and environmental factors associated with stereotypic behavior and fecal glucocorticoid metabolite levels in zoo housed polar bears. Applied Animal Behaviour Science 147:268-77.

Sherwen S.L, Harvey TJ, Magrath MJ.L, Butler KL, Fanson KV, Hemsworth PH (2015) Effects of visual contact with zoo visitors on black-capped capuchin welfare Applied Animal Behaviour Science 167:65-73.

Sherwen SL, Hemsworth PH, Butler KL, Fanson KV, Magrath MJL (2015) Impacts of visitor number on kangaroos housed in free-range exhibits. Zoo Biology 34:287-95.

Sherwen SL, Magrath MJL, Butler KL. Hemsworth PH (2015b) Little penguins, Eudyptula minor, show increased avoidance aggression and vigilance in response to zoo visitors. Applied Animal Behaviour Science168:71-76.

Sherwen SL, Magrath, MJL, Butler KL, Phillips, CJ, Hemsworth PH (2014) A multi-enclosure study investigating the behavioural response of meerkats to zoo visitors. Applied Animal Behaviour Science 156:70-77.

Soriano Al, Vinyoles D, Maté C (2013) The influence of visitors on behavior and on the use of space in two species of ursids: a management question? International Zoo News 60:341-56.

Soriano Al, Vinyoles D, Maté C (2017) Abnormal behaviours in two captive brown bear (Ursus arctos Linnaeus, 1758) females: Individual differences and seasonal variations. Zoologische Garten 86:88-101.

Stevens JMG, Thyssen A, Laevens $H$, Vervaecke $H$ (2013) The influence of zoo visitor numbers on the behaviour of harbour seals (Phoca vitulina). Journal 
Zoo and Aquarium Research 1:31-34.

Sutherland WJ, Pullin AS, Dolman PM, Knight TM (2004) The need for evidence-based conservation. Trends in Ecology \& Evolution 19:305-308.

Tennant KS, Segura VD, Morris MC, Snyder KD, Bocian D, Maloney D, Maple TL (2018) Achieving optimal welfare for the Nile hippopotamus (Hippopotamus amphibius) in North American zoos and aquariums. Behavioural Processes 156:83-95.

Tetley CL. O'Hara SJ (2012) Ratings of animal personality as a tool for improving the breeding, management and welfare of zoo mammals. Animal Welfare 21:463-76.

Tribe A, Booth R (2003) Assessing the role of zoos in wildlife conservation Human Dimensions of Wildlife 8:65-74.

van der Weyde LK, Martin GB, Paris MCJ (2016) Monitoring stress in captive and free-ranging African wild dogs (Lycaon pictus) using faecal glucocorticoid metabolites. General and Comparative Endocrinology 226:50-55.

Vaz J, Narayan EJ, Kumar RD, Thenmozh K, Thiyagesai K, Baskaran N (2017) Prevalence and determinants of stereotypic behaviours and physiological stress among tigers and leopards in Indian zoos. PlosOne 12(4):e0174711.

Wallace MP, Clark M, Vargas J, Porras MC (2007) Release of puppet-reared California condors in Baja California, Mexico: evaluation of a modified rearing technique. In: Mee A, Hall LS (eds) California Condors in the 21st Century, Series in Ornithology, No. 2. American Ornithologists Union Fayettevile Ark, USA, pp 227-242.

Warwick C, Frye FL, Murphy JB (2013) Health and Welfare of Captive Reptiles. Chapman \& Hall, UK.

Weiss A, Adams MJ, King JE (2011) Happy orang-utans live longer lives. Biology Letters 7:872-74.

Weiss A, King JE, Perkins L (2006) Personality and subjective well-being in orangutans (Pongo pygmaeus and Pongo abelii). Journal of Personality and Social Psychology 90:501-11.

Wells DL (2005) A note on the influence of visitors on the behaviour and welfare of zoo-housed gorillas. Applied Animal Behaviour Science 93:13-17.

Whitham JC, Wielebnowski N (2009) Animal-based welfare monitoring: using keeper ratings as an assessment tool. Zoo Biology 28:545-60.

Whitham JC, Wielebnowski N (2013) New directions for zoo animal welfare science. Applied Animal Behaviour Science 147:247-60.

Wielebnowski N (2003) Stress and distress: evaluating their impact for the well-being of zoo animals. Journal of the American Veterinary Medical Association 223:973-77.

Wielebnowski NC, Fletchall N, Carlstead K, Busso JM, Brown JL (2002) Noninvasive assessment of adrenal activity associates with husbandry and behavioral factors in the North American clouded leopard population. Zoo Biology 21:77-98.
Wolfe BA, Aguilar RF, Aguirre AA, Olsen GH, Blumer ES (2012) Sorta situ. The New Reality of Management Conditions for Wildlife Populations in the Absence of "Wild" Spaces. In: Aguirre AA, Ostfeld RS, Daszak P (eds) New Directions in Conservation Medicine. Applied Cases of Ecological Health. Oxford University Press, USA, pp 576-589.

Wolfensohn S, Shotton J, Bowley H, David S, Thompson S, Justice WSM (2018) Assessment of welfare in zoo animals: Towards optimum quality of life. Animals 8(110):doi:10.3390.

Wood W (1998) Interactions among environmental enrichment, viewing crowds, and zoo chimpanzees (Pan troglodytes). Zoo Biology 17:211-30.

World Association of Zoos and Aquariums (WAZA) (2005) Building a Future for Wildlife. The World zoo Conservation Strategy. World Aquaria and Zoos Association Executive Office, Switzerland.

World Association of Zoos and Aquariums (WAZA) (2016) Guidelines for the Use of Animals in Visitor Interactions. Switzerland WAZA: Executive Office. 2016. http://www.zoosafrica.com/about/projects.html. Accessed on June 28, 2018.

Yasuda H (2013) Negotiating entertainment and education: A zoo in Japan. International Journal of Culture, Tourism and Hospitality Research 7:105-12. Yeates JW, Main DCJ (2008) Assessment of positive welfare: a review. The Veterinary Journal 175:293-300.

Yon L, Williams E, Harvey ND, Asher L (2019) Development of a behavioural welfare assessment tool for routine use with captive elephants. PLoS ONE 14(2):e0210783.

Young KM, Walker SL, Lanthier C, Waddell WJ, Monfort SL, Brown JL (2004) Noninvasive monitoring of adrenocortical activity in carnivores by fecal glucocorticoid analyses. General and Comparative Endocrinology 137:14865.

Young RJ (2003) Environmental Enrichment for Captive Animals. Blackwell Science, Oxford.

Zimmermann A (2010) The role of zoos in contributing to in situ conservation. In: Kleiman D, Thompson K, Baer K (ed) Wild Mammals in Captivity: Principles and Techniques for Zoo Management, 2nd ed. University of Chicago Press, Chicago, pp 268-287.

Zoo and Aquarium Association Animal Welfare (2020) Assessment Tool; Zoo and Aquarium Association Australasia Accreditation 2020. https://www.zooaquarium.org.au/index.php/accreditation-2020/. Accessed on: April 27, 2020.

Zwijacz-Kozica T, Selva N, Barja I, Silván G, Martínez-Fernández L, Illers JC, Jodlowski M (2013) Concentration of fecal cortisol metabolites in chamois in relation to tourist pressure in Tartra National Park (South Poland). Acta Theriologica 58:215-22. 